\title{
IFKhAN-140, a chamber corrosion inhibitor for brass
}

\section{D.S. Kuznetsov, O.A. Goncharova, N.N. Andreev, ${ }^{*}$ N.P. Andreeva and S.S. Vesely}

Federal State Budgetary Scientific Institution "A.N. Frumkin Institute of Physical Chemistry and Electrochemistry" of the Russian Academy of Sciences

*E-mail: n.andreev@mail.ru

\begin{abstract}
A combination of accelerated electrochemical (potentiodynamic and impedance) and corrosion methods (performed under intense condensation of moisture and neutral salt fog), as well as outdoor tests were used to study the protective aftereffect of adsorption films formed on brass on exposure to a mixture of octadecylamine and benzotriazole ( IFKhAN-140) at 100 and $120^{\circ} \mathrm{C}$. It was shown that the components of IFKhAN-140 synergistically enhance the protective aftereffect of the adsorption layers. The protective aftereffect of the adsorbed inhibitor films is most pronounced at a chamber treatment temperature of $120^{\circ} \mathrm{C}$, although at $100^{\circ} \mathrm{C}$ the corrosion inhibition factors are also high. The protective properties of the inhibitor at the chamber treatment temperatures studied increase symbiotically with the treatment duration. However, chamber treatment for more than one hour leads to undesirable metal tarnishing. Using the ellipsometry method, it was found that the thickness of the surface films on brass that provides a significant increase in its corrosion resistance does not exceed $20 \mathrm{~nm}$. The high protective properties of IFKhAN-140 toward steel, copper and brass at once allow it to be regarded as a formulation suitable for the protection of polymetallic products.
\end{abstract}

Keywords: brass, atmospheric corrosion, corrosion inhibitors, chamber corrosion inhibitors, vapor-phase protection, chamber protection.

Received: January 24, 2020. Published: February 20, 2020

doi: $\underline{10.17675 / 2305-6894-2020-9-1-19}$

\section{Introduction}

Corrosion inhibitors are widely used to protect metals from atmospheric corrosion $[1,2]$. Chamber processing (CT) is a new method for the inhibitory protection of metals. It involves short-term treatment of metal products in a closed volume (chamber) by inhibitor vapors at elevated temperatures. Therefore, it represents a variety of vapor-phase inhibitor protection. The adsorption films formed during CT on metals with an optimally selected chamber inhibitor (CIN), temperature and treatment time manifest a protective aftereffect (PAE) sufficient for the temporary protection of metal products [3].

CT has a number of advantages in comparison with the traditional vapor-phase protection by volatile corrosion inhibitors. The most important one is the lack of the need to pack metal products and an inhibitor source air-tightly for the entire time of protection. Furthermore, high (typically above $100^{\circ} \mathrm{C}$ ) $\mathrm{CT}$ temperatures $\left(t_{\mathrm{CT}}\right)$ allow one to use 
compounds that are unsuitable as volatile inhibitors due to low vapor pressures under ordinary conditions.

Development of the chamber treatment method was intensely performed for the past three years, and CINs suitable for the protection of monometallic products made of steel, copper, aluminum alloys, magnesium and zinc [4-7] have already been found. However, versatile CINs capable of simultaneously protecting several metals and alloys are not yet available. Finding such CINs is the task that is most important for the development of the method.

Previously, it was shown that a synergistic mixture of octadecylamine and benzotriazole (IFKhAN-140 chamber inhibitor) could be used for the chamber protection of copper and steel and the optimal conditions for the CT of these metals were determined $[5,6]$. The purpose of this work is to assess the prospects of using this CIN for brass protection. The focus on the creation of a versatile CIN determined the choice of the $t_{\mathrm{CT}}$ of this metal. It was of primary interest to determine the optimum temperatures for copper and steel treatment $\left(100\right.$ and $\left.120^{\circ} \mathrm{C}\right)$. At $t_{\mathrm{CT}}$ above $120^{\circ} \mathrm{C}$, the PAE of inhibitor adsorption films on steel decreased and copper underwent tarnishing already during the CT. At $t_{\mathrm{CT}}$ below $100^{\circ} \mathrm{C}$, the equilibrium adsorption films of CINs on both metals did not have a pronounced PAE.

\section{Experimental}

All the reagents used in this study were of "pure" grade.

Samples and electrodes made of L63 brass were used in the studies. The composition of the brass is presented in Table 1 .

Table 1. L63 brass composition (mass \%).

\begin{tabular}{ccccccc}
\hline $\mathbf{C u}$ & $\mathbf{P b}$ & $\mathbf{F e}$ & $\mathbf{S b}$ & $\mathbf{B i}$ & $\mathbf{P}$ & $\mathbf{Z n}$ \\
\hline $60.5-63.5$ & 0.08 & 0.15 & 0.005 & 0.002 & 0.002 & remainder \\
\hline
\end{tabular}

Cylindrical electrodes with a threaded joint at one of the butt-ends were used in electrochemical experiments. The electrodes were mounted with epoxy resin to prevent exposure of the side surfaces to the electrolyte during an experiment. The lower butt-end of the cylinder with a surface area of $0.5 \mathrm{~cm}^{2}$ served as the working surface.

Planar samples $30 \times 50 \times 4 \mathrm{~mm}$ in size, with holes for fastening in the test cells and chambers, were prepared for the corrosion tests.

Before the chamber treatment, the samples and electrodes were polished with sandpaper of various grit sizes to a mirror finish, degreased with acetone, and dried. The prepared samples and electrodes were mounted in sealed 0.5 liter glass cells, each containing a weighted portion $(0.5 \mathrm{~g})$ of the CIN. The cells were placed in a drying chamber heated to 100 or $120^{\circ} \mathrm{C}$. The metal was exposed in the drying chamber for a 
period $\left(\tau_{\mathrm{CT}}\right)$ from 15 minutes to 2 hours. After that, the cells were removed from the oven. The samples were taken out, kept at room temperature for 24 hours, and tested.

The PAE of adsorption films was estimated in accelerated electrochemical (potentiodynamic and impedance) and corrosion tests (under conditions of intense moisture condensation and neutral salt fog), as well as in outdoor experiments.

The potentiodynamic experiments were performed using an IPC-pro potentiostat (made in Russian Federation) and a standard three-electrode cell with divided electrode spaces. A platinum wire served as the auxiliary electrode. The potentials $(E)$ were measured against a saturated silver/silver chloride reference electrode and then converted to the normal hydrogen scale. The experiments were carried out in a neutral borate buffer solution $(\mathrm{pH}=7.36)$ containing $0.001 \mathrm{M} \mathrm{NaCl}$. The electrodes were placed in a cell with the electrolyte, kept for 5 min until the potential stabilized $\left(E_{\mathrm{CT}}\right)$, and polarized in the anodic direction from this potential. The potential sweep rate was $0.2 \mathrm{mV} / \mathrm{s}$.

Electrochemical impedance spectra were obtained using an Autolab PGSTAT302 potentiostat with a FRA32M module. The experiments were carried out in a cell, on electrodes, and under conditions similar to those used in the potentiodynamic experiments. The frequency was varied in the range from $10 \mathrm{kHz}$ to $0.01 \mathrm{~Hz}$, and the alternating voltage amplitude was $10 \mathrm{mV}$. The electrochemical impedance parameters were calculated using the equivalent circuit that is widely used to describe the impedance spectra of brass (Figure 1) [8-10].

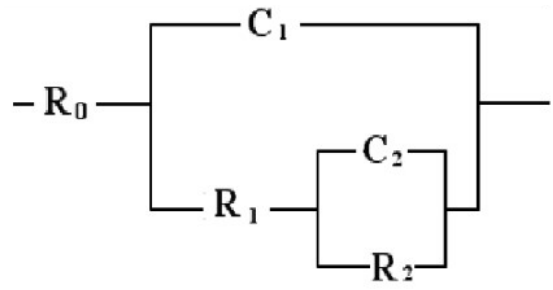

Figure 1. The equivalent circuit used to calculate the impedance parameters.

Here $R_{0}$ is the solution resistance, $C_{1}$ is the double layer capacitance, $R_{1}$ is the charge transfer resistance, and $R_{2} / C_{2}$ correspond to the adsorbed inhibitor layer.

The results were processed and the equivalent circuit parameters were determined using the NOVA program.

The degree of brass electrode protection was calculated by the equation:

$$
Z=\left(R_{\mathrm{inh}}-R_{\mathrm{bg}}\right) / R_{\mathrm{inh}} \cdot 100 \%
$$

where $R_{\mathrm{bg}}$ and $R_{\text {inh }}$ are the total resistances of "metal-electrolyte" interphase interaction $\left(R_{1}+R_{2}\right)$ after thermal treatment of the electrode in the absence and in the presence of a CIN, respectively.

The PAE of metal treatment in the inhibitor vapors was also studied under neutral salt fog conditions. The experiments were carried out in a WEISS SC 450 chamber at room temperature. Each cycle included 15-minute spraying of 3\% sodium chloride solution 
followed by 45 -minute exposure of specimens in the resulting salt fog. The samples were inspected at a time point of 55 minutes after the start of each cycle.

Prior to corrosion tests with recurrent moisture condensation, the samples were mounted on nylon threads to the lids of sealed glass cells so that they did not contact each other and the cell walls. The volume of each cell was $600 \mathrm{ml}$. Hot water $\left(0.1 \mathrm{~L}, 50^{\circ} \mathrm{C}\right)$ was poured into each cell. Once every 24 hours, the water that cooled down was replaced with hot water. The samples were inspected hourly without opening the cells during the first day of the experiments, and then once a day simultaneously with the water change.

The outdoor corrosion tests were carried out in a louvre box at the Moscow Corrosion Station. The samples were inspected once a week. The test duration was 9 months.

In corrosion tests of all kinds, the time until the first corrosion damage appeared on the brass $\left(\tau_{\text {prot }}\right)$ was recorded.

The variation in the thickness $(\Delta d)$ of films formed on brass under specific conditions was measured with a manual Gartner ellipsometer with light beam modulation and advanced light detection. A diode-pumped solid-state laser, model LSM-S-111-10-NNP25, with a wavelength of $540 \mathrm{~nm}$ was used as the light source. The variation in the ellipsometric angles $\Delta$ and $\Psi$ during the CT was recorded. The thicknesses of the inhibitor and oxide films were calculated using the Ellipsometry Calculation Spread Sheet (E. Kondoh).

All the values presented in this paper are the averages of 5-7 independent experiments.

\section{Results and discussion}

Heat treatment at 100 and $120^{\circ} \mathrm{C}$ for up to one hour, both in the presence IFKhAN-140 and without it, did not affect the appearance of the samples. They retained their original luster. A longer exposure of brass in IFKhAN-140 vapors at these temperatures was accompanied by surface tarnishing that is undesirable from a practical point of view. As a result, 1 hour was chosen as the maximum $\tau_{\mathrm{CT}}$ of brass in this study.

Anodic potentiodynamic polarization is considered to be the fastest method for estimating the efficiency of corrosion inhibitors. The polarization curves obtained by this method are shown in Figure $2 \mathrm{a}$ and $\mathrm{b}$, and the $E$ values characterizing these curves are given in Table 2.

The $E_{\mathrm{CT}}$ of a brass electrode that did not undergo CT was $0.05 \pm 0.01 \mathrm{~V}$. Anodic polarization of the alloy was not accompanied by active dissolution. After a passive region with a length of $0.15-0.16 \mathrm{~V}$, first oscillations and then a sharp increase in the current density $(i)$ associated with pit formation $(\mathrm{PF})$ were observed on the polarization curves. Visual inspection of the electrodes confirmed that this process actually took place. One could see local dissolution sites in the form of black dots on their surfaces.

Heat treatment of brass in the absence of IFKhAN-140 slightly ennobled $E_{\mathrm{CT}}$ and inhibited PF, also to a small extent. The inhibition of the alloy anodic dissolution was more noticeable at $t_{\mathrm{CT}}=120^{\circ} \mathrm{C}$. 
Regardless of duration and temperature, CT of brass with the mixed inhibitor led to a somewhat larger $E_{\mathrm{CT}}$ ennoblement (by about $0.08 \mathrm{~V}$ compared to the electrodes that did not undergo heat treatment). It indicates that the adsorption films of IFKhAN-140 predominantly suppress the anodic process.

Analysis of polarization curves themselves also indicates that IFKHAN-140 inhibits the anodic process.

After CT for 15 and 30 minutes at both $t_{\mathrm{CT}}$ values used, as well as for 60 minutes at $100^{\circ} \mathrm{C}$, the polarization curves contained an extended passive region changing to a region of $i$ oscillations due to PF, like in the case described above. The local dissolution sites formed after $\mathrm{CT}$ acquired the ability to be repassivated, and the instant of their nucleation was accompanied by very minor $i$ jumps and/or oscillations. No sharp increase in $i$ was observed on the polarization curves up to oxygen evolution potentials.
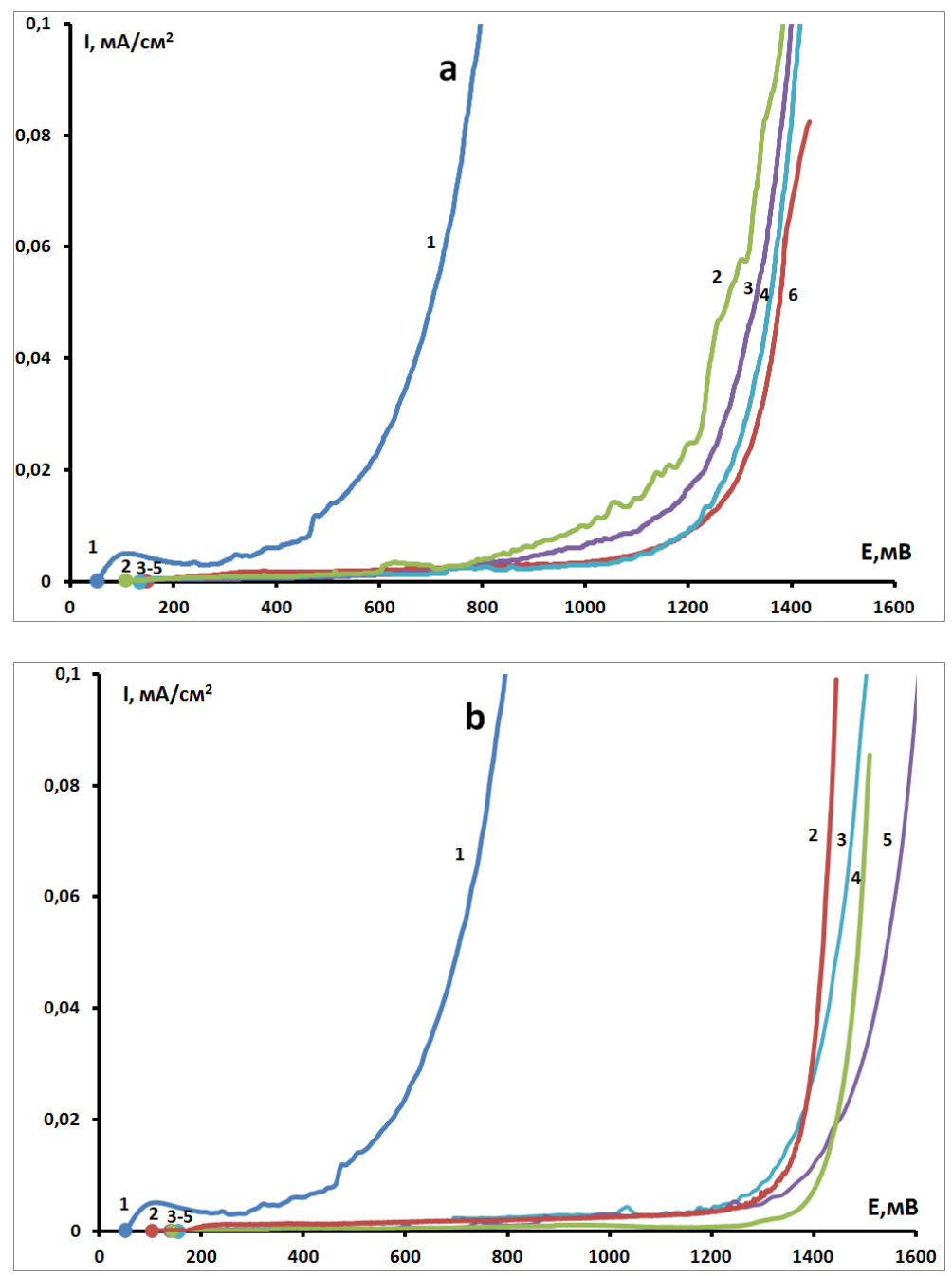

Figure 2. Polarization curves of L63 electrodes recorded without heat treatment -2 , after heat treatment for $60 \mathrm{~min}$ without a CIN -1 , and after CT for $15 \mathrm{~min}-3 ; 30 \mathrm{~min}-4$; $60 \min -5 . \mathrm{a}-100^{\circ} \mathrm{C} ; \mathrm{b}-120^{\circ} \mathrm{C}$. 
Sometimes the $i$ oscillations caused by PF were comparable with those due to nonideal grounding of the system and electromagnetic pickups in electrolytes that did not contain anions capable of initiating local dissolution. This made it difficult to accurately determine the pit formation potential $\left(E_{\mathrm{PF}}\right)$ on the polarization curves. The $E_{\mathrm{PF}}$ values determined from the first $i$ jump sometimes differed by $0.20-0.40 \mathrm{~V}$ between similar experiments. Nevertheless, for both $t_{\mathrm{CT}}$ values we observed a clear trend to PF inhibition manifested as an ennoblement of the range of possible $E_{\mathrm{PF}}$ values with increasing $\tau_{\mathrm{CT}}$. Moreover, the CT efficiency increased with an increase in temperature. In fact, a half-hour $\mathrm{CT}$ of electrodes at $120^{\circ} \mathrm{C}$ completely inhibited the local dissolution under anodic polarization.

Table 2. Parameters of anodic polarization curves after CT of brass electrodes under different conditions.

\begin{tabular}{ccc}
\hline CT conditions & $\boldsymbol{E}_{\mathbf{C T}}, \mathbf{V}$ & $\boldsymbol{E}_{\mathbf{P F}}, \mathbf{V}$ \\
\hline Without heat treatment & 0.05 & 0.20 \\
\hline & $\boldsymbol{t}_{\mathbf{C T}}=\mathbf{1 0 0}^{\circ} \mathbf{C}$ & \\
\hline 60 min without a CIN & 0.10 & 0.44 \\
15 min with IFKhAN-140 & 0.13 & $0.6 \pm 0.10$ \\
30 min with IFKhAN-140 & 0.13 & $0.7 \pm 0.10$ \\
60 min with IFKhAN-140 & 0.14 & $0.9 \pm 0.05$ \\
\hline & $\boldsymbol{t}_{\mathbf{C T}}=\mathbf{1 2 0}^{\circ} \mathbf{C}$ & \\
\hline 60 min without a CIN & 0.11 & 0.51 \\
15 min with IFKhAN-140 & 0.13 & - \\
30 min with IFKhAN-140 & 0.14 & - \\
60 min with IFKhAN-140 & 0.14 &
\end{tabular}

Thus, the anodic potentiodynamic polarization method testified to a PAE of adsorption films of the mixed inhibitor associated with the inhibition of PF initiation. However, the quantitative parameters of the inhibition of brass dissolution could only be estimated with a considerable error. This did not allow us to accurately determine the optimum conditions of brass chamber treatment.

The estimates of the PAE of adsorbed films of IFKhAN-140 using electrochemical impedance spectroscopy were more informative.

The hodographs of brass electrodes that were not heat treated or were heat treated without a CIN had the shape of slightly deformed semicircles (Figure 3 a and b) and were adequately described by an equivalent circuit shown in Figure 1 . The fit between the experimental and calculated data was no worse than $98 \%$. 

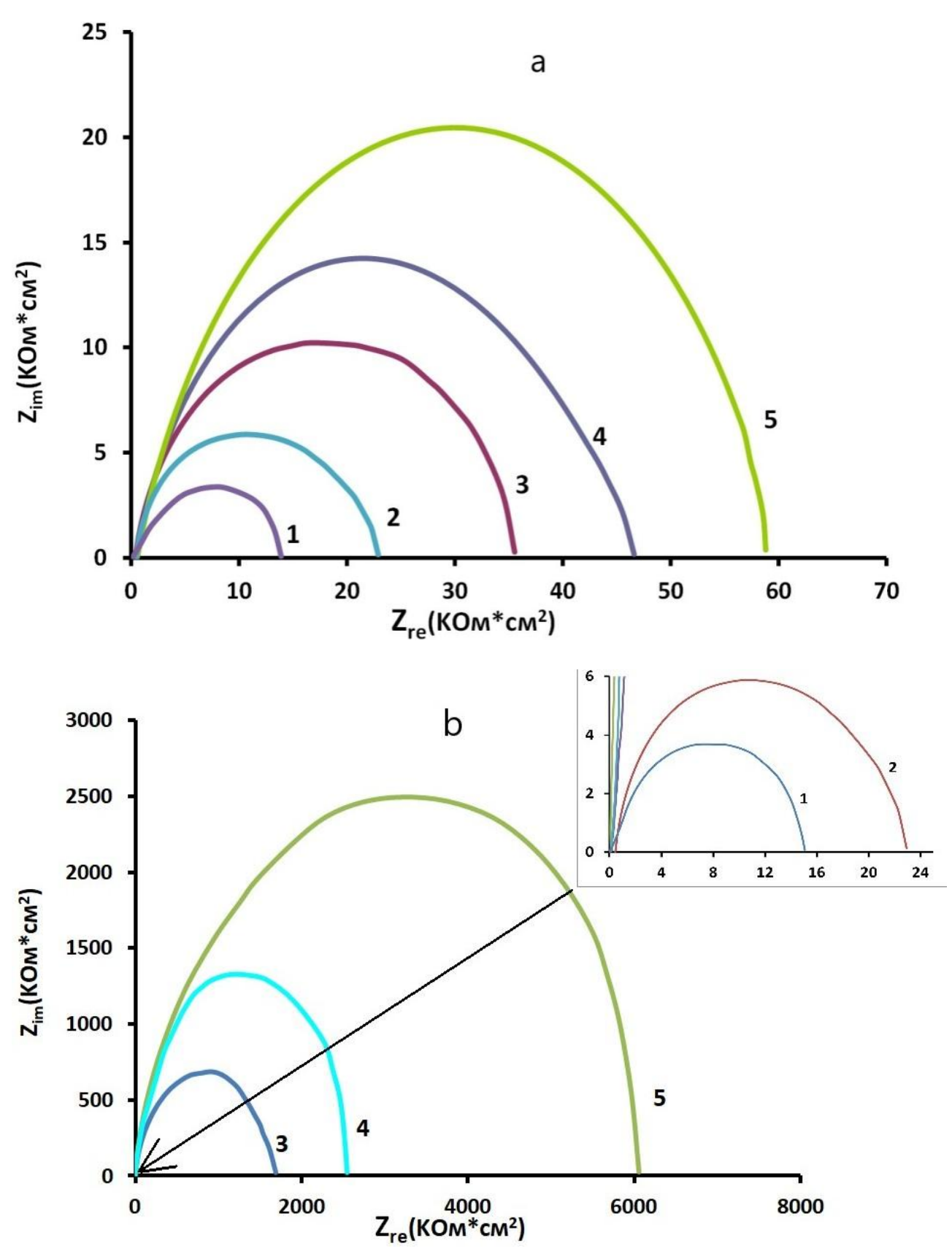

Figure 3. Nyquist plots of L63 electrodes recorded without heat treatment-1, after heat treatment for $60 \mathrm{~min}$ without a CIN - 2, and after CT for $15 \min -3 ; 30 \mathrm{~min}-4 ; 60 \mathrm{~min}-5$. $\mathrm{a}-100^{\circ} \mathrm{C} ; \mathrm{b}-120^{\circ} \mathrm{C}$.

Addition of IFKhAN-140 into the chamber resulted in an increase in the diameter of the semicircles. The low-frequency resistive impedance regions shifted to higher values, whereas the capacitive ones decreased. The accuracy of the experimental data fit by the equivalent circuit did not decrease.

The results of the calculation of impedance parameters presented in Table 3 indicate that the $R_{1}$ and $R_{2}$ values increase whereas $C_{1}$ and $C_{2}$ decrease. The $R_{1}$ and $R_{2}$ variations 
were more pronounced in the case of $t_{\mathrm{CT}}=120^{\circ} \mathrm{C}$. For both $t_{\mathrm{CT}}$ values, the values of $R_{1}$ and $R_{2}$ grew symbiotically with $\tau_{\mathrm{CT}}$.

According to [8-18], an increase in $R_{1}$ and a decrease in $C_{2}$ can be interpreted as corrosion inhibition. A decrease in the double layer capacitance $C_{1}$ indicates that the CIN is adsorbed on the metal, which reduces the fraction of its electrochemically active surface. The growth of $R_{2}$ indicates that charge transfer slows down due to the formation of a protective inhibitor layer.

In general, based on the calculated values of $R_{1}$ and $R_{2}$, the values of $Z$ indicate a high efficiency of the mixed CIN against brass corrosion that is more pronounced at $t_{\mathrm{CT}}=120^{\circ} \mathrm{C}$. This gave us a reason for testing the efficiency of IFKhAN-140 directly by corrosion methods.

Table 3. Impedance parameters calculated for brass electrodes that underwent chamber treatment in different modes.

\begin{tabular}{|c|c|c|c|c|c|}
\hline CT conditions & $\begin{array}{c}R_{1}, \\
\mathrm{kOhm} \cdot \mathrm{cm}^{2}\end{array}$ & $C_{1}, \mu \mathrm{F}$ & $\begin{array}{c}R_{2}, \\
\mathrm{kOhm} \cdot \mathrm{cm}^{2}\end{array}$ & $C_{2}, \mu \mathrm{F}$ & $Z, \%$ \\
\hline Without heat treatment & 0.369 & 3.29 & 5.286 & 9.77 & - \\
\hline \multicolumn{6}{|c|}{$t_{\mathrm{CT}}=100^{\circ} \mathrm{C}$} \\
\hline 60 min without a CIN & 0.596 & 3.28 & 9.934 & 7.76 & 46.29 \\
\hline 15 min with IFKhAN-140 & 13.173 & 0.48 & 21.370 & 0.3 & 83.62 \\
\hline 30 min with IFKhAN-140 & 20.114 & 0.47 & 49.432 & 0.28 & 91.86 \\
\hline 60 min with IFKhAN-140 & 29.264 & 0.45 & 57.365 & 0.28 & 93.47 \\
\hline \multicolumn{6}{|c|}{$t_{\mathrm{CT}}=120^{\circ} \mathrm{C}$} \\
\hline 60 min without a CIN & 0.792 & 2.87 & 12.874 & 6.09 & 58.61 \\
\hline 15 min with IFKhAN-140 & 1856 & 0.31 & 10400 & 0.33 & 99.95 \\
\hline 30 min with IFKhAN-140 & 3220 & 0.32 & 15500 & 0.34 & 99.98 \\
\hline 60 min with IFKhAN-140 & 5130 & 0.3 & 21400 & 0.35 & 99.99 \\
\hline
\end{tabular}

The results of corrosion experiments in the salt fog chamber are given in Table 4.

The black corrosion spots on the samples that did not undergo heat treatment and that were heat treated for one hour without a CIN already appeared during the first test cycle. The CT of brass in the presence of either BTA and ODA alone did not affect the corrosion resistance of brass, regardless of $t_{\mathrm{CT}}$ and $\tau_{\mathrm{CT}}$. Upon addition of BTA and ODA together into the chamber, a synergistic increase in the PAE of adsorption films was observed for brass, similarly to steel or copper $[12,13]$. In fact, CT for one hour at a temperature of $100^{\circ} \mathrm{C}$ provided total protection of brass for 6 test cycles, while at $120^{\circ} \mathrm{C}-$ for 13 cycles. 
Table 4. Effect of CT conditions on the results of corrosion experiments in a salt spray chamber.

\begin{tabular}{|c|c|}
\hline CT conditions & $\tau_{\text {prot }}$, hours \\
\hline Without treatment & 1 \\
\hline \multicolumn{2}{|c|}{$t_{\mathrm{CT}}=100^{\circ} \mathrm{C}$} \\
\hline 60 min without a CIN & 1 \\
\hline 15 min with ODA & 1 \\
\hline 30 min with ODA & 1 \\
\hline 60 min with ODA & 1 \\
\hline 15 min with BTA & 1 \\
\hline 30 min with BTA & 1 \\
\hline 60 min with BTA & 1 \\
\hline 15 min with IFKhAN-140 & 2 \\
\hline 30 min with IFKhAN-140 & 3 \\
\hline 60 min with IFKhAN-140 & 6 \\
\hline \multicolumn{2}{|c|}{$t_{\mathrm{CT}}=120^{\circ} \mathrm{C}$} \\
\hline 60 min without a CIN & 1 \\
\hline 15 min with ODA & 1 \\
\hline 30 min with ODA & 1 \\
\hline 60 min with ODA & 1 \\
\hline 15 min with BTA & 1 \\
\hline 30 min with BTA & 1 \\
\hline 60 min with BTA & 1 \\
\hline 15 min with IFKhAN-140 & 3 \\
\hline 30 min with IFKhAN-140 & 5 \\
\hline 60 min with IFKhAN-140 & 13 \\
\hline
\end{tabular}

An increase in the duration of CT with IFKhAN-140 beneficially affected the corrosion resistance of brass in terms of pitting corrosion.

In the experiments with recurrent moisture condensation that are less stringent than the salt spray tests, the PAE of IFKhAN-140 adsorption films was even more noticeable. Local corrosion was also observed in these tests: during the first hour of brass exposure under the test conditions, black dots appeared on the samples that did not undergo heat treatment. For samples treated at $t_{\mathrm{CT}}=100$ and $120^{\circ} \mathrm{C}$ without a CIN, the first pits were observed on brass surface 2 hours after the start of the experiment. 
Addition of IFKhAN-140 to the chamber increased the corrosion incubation time to 59 days (i.e., 708 -fold) at $t_{\mathrm{CT}}=100^{\circ} \mathrm{C}$ and to 93 days $\left(1116\right.$-fold) at $120^{\circ} \mathrm{C}$.

Thus, accelerated corrosion tests confirmed the high PAE of adsorption films formed on brass upon $\mathrm{CT}$ with a benzotriazole-octadecylamine mixture and allowed us to determine that one-hour CT at $120^{\circ} \mathrm{C}$ are the optimal conditions in terms of protection. This gave us grounds to set up outdoor corrosion tests.

These tests confirmed the feasibility of using the CT of brass with a octadecylaminebenzotriazole mixture for its temporary protection. Throughout the entire period of exposure under outdoor conditions ( 9 months), brass samples that underwent $\mathrm{CT}$ at $120^{\circ} \mathrm{C}$ showed no corrosion.

It is significant that the PAE of IFKhAN-140 described above is a consequence of the formation of very thin (nanoscale) adsorption films on the alloy surface. This follows from ellipsometry data.

According to [19-21], the thickness of the oxide film on brass formed during the preparation of samples for corrosion and electrochemical experiments is $4-5 \mathrm{~nm}$. The changes in the thickness of the surface layers formed during heat treatment without a CIN and during the CT of brass in the presence of IFKhAN-140 are given in Table 5.

Heat treatment of brass without a CIN led to the growth of a surface oxide. Its thickness increased markedly with exposure time of the alloy in the drying cabinet. The oxide growth was more pronounced at $120^{\circ} \mathrm{C}$. In fact, the $\Delta d$ value reached $3.3 \mathrm{~nm}$ after one-hour heat treatment at this temperature.

Addition of IFHAN-140 to the system nearly prevented the growth of the oxide film at $t_{\mathrm{CT}}=100^{\circ} \mathrm{C}$ and markedly inhibited it at $120^{\circ} \mathrm{C}$. In this case, the thickness of the CIN adsorption films formed on the surface did not exceed $17 \mathrm{~nm}$.

\section{Conclusions}

1. Chamber treatment in IFHAN-140 vapors efficiently inhibits the atmospheric corrosion not only of steel and copper, but also of brass, which makes it possible to consider it as a versatile CIN.

2. The components of IFKhAN-140 synergistically enhance the PAE of the adsorption layers formed during the CT.

3. The increase in the corrosion resistance of brass upon CT is due to the formation of nanoscale adsorption layers of IFKhAN-140.

4. The PAE of adsorption films of IFKhAN-140 on brass is most pronounced at $t_{\mathrm{CT}}=120^{\circ} \mathrm{C}$, though the corrosion inhibition factors are also rather large at $t_{\mathrm{CT}}=100^{\circ} \mathrm{C}$.

5. For the $t_{\mathrm{CT}}$ values studied, the PAE of adsorption layers of IFHAN-140 increases symbiotically to $\tau_{\mathrm{CT}}$. However, chamber treatment for more than one hour leads to undesirable tarnishing of the metal. 
Table 5. Effect of CT mode on the variation in the thickness of surface layers.

\begin{tabular}{|c|c|c|}
\hline \multirow{2}{*}{ CT conditions } & \multicolumn{2}{|c|}{$\Delta d, \mathbf{n m}$} \\
\hline & Surface oxide & CIN films \\
\hline \multicolumn{3}{|c|}{$t_{\mathrm{CT}}=100^{\circ} \mathrm{C}$} \\
\hline 15 min without a CIN & 0.1 & - \\
\hline 30 min without a CIN & 0.5 & - \\
\hline 60 min without a CIN & 0.7 & - \\
\hline 15 min with IFKhAN-140 & $<0.1$ & 4.4 \\
\hline 30 min with IFKhAN-140 & $<0.1$ & 6.3 \\
\hline 60 min with IFKhAN-140 & $<0.1$ & 6.4 \\
\hline \multicolumn{3}{|c|}{$t_{\mathrm{CT}}=120^{\circ} \mathrm{C}$} \\
\hline 15 min without a CIN & 1.9 & - \\
\hline 30 min without a CIN & 2.5 & - \\
\hline 60 min without a CIN & 3.3 & - \\
\hline 15 min with IFKhAN-140 & 0.5 & 4.0 \\
\hline 30 min with IFKhAN-140 & 0.5 & 5.1 \\
\hline 60 min with IFKhAN-140 & 1.5 & 17.0 \\
\hline
\end{tabular}

\section{References}

1. I.L. Rozenfel'd and V.P. Persiantseva, Inhibitors of atmospheric corrosion, Nauka, 1985, Moscow (in Russian).

2. A.A. Mikhailov, Yu.M. Panchenko and Yu.I. Kuznetsov, Atmospheric corrosion and protection of metals, R.V. Pershin Publishing House, 2016, Tambov (in Russian).

3. Yu. Kuznetsov, O. Goncharova, A. Luchkin, S. Vesely and N. Andreev, Vapor-phase protection of metals from atmospheric corrosion by low-volatile organic inhibitors, Eurocorr-2018, 121-167.

4. O.A. Goncharova, Yu.I. Kuznetsov, N.N. Andreev, A.Yu. Luchkin, N.P. Andreeva and D.S. Kuznetsov, A new corrosion inhibitor for zinc chamber treatment, Int. J. Corros. Scale Inhib., 2018, 7, no. 3, 340-351. doi: 10.17675/2305-6894-2018-7-3-5

5. O.A. Goncharova, A.Yu. Luchkin, Yu.I. Kuznetsov, N.N. Andreev, N.P. Andreeva and S.S. Vesely, Octadecylamine, 1,2,3-benzotriazole and a mixture thereof as chamber inhibitors of steel corrosion, Int. J. Corros. Scale Inhib., 2018, 7, no. 2, $203-$ 212. doi: $\underline{10.17675 / 2305-6894-2018-7-2-7}$ 
6. O.A. Goncharova, N.N. Andreev, A.Yu. Luchkin, Yu.I. Kuznetsov, N.P. Andreeva and S.S. Vesely, Protection of copper by treatment with hot vapors of octadecylamine, 1,2,3-benzotriazole, and their mixtures, Mater. Corros., 2019, 70, no. 1, 161-168. doi: $10.1002 / \mathrm{maco} .201810366$

7. O.A. Goncharova, A.Yu. Luchkin, N.N. Andreev, N.P. Andreeva and S.S. Vesely, Triazole derivatives as chamber inhibitors of copper corrosion, Int. J. Corros. Scale Inhib., 2018, 7, no. 4, 657-672. doi: 10.17675/2305-6894-2018-7-4-12

8. M. Galai, J. Choucri, Y. Hassani, H. Benqlilou, I. Mansouri, B. Ouaki, M. Ebn Touhami, C. Monticelli and F. Zucchi, Moisture content and chloride ion effect on the corrosion behavior of fitting brass (gate valves) used as a connection of PVC's conduits in aggressive sandy soil, Chem. Data Collect., 2019, 19, 1-34. doi: 10.1016/j.cdc.2018.11.013

9. N. Ben Seddik, I. Raissouni, K. Draoui, A. Aït Aghzzaf, A. Chraka, B. Aznag, F. Chaouket and D. Bouchta, Anticorrosive performance of lanthanum ions intercalated Stevensite clay on brass in 3\% NaCl medium, Mater. Today: Proc., 2019. doi: 10.1016/j.matpr.2019.08.085

10. Fan Hongqiang, Li Shuying, Zhao Zongchang, Wang Hua, Shi Zhicong and Zhang Lin, Inhibition of brass corrosion in sodium chloride solutions by self-assembled silane films, Corros. Sci., 2011, 53, 4273-4281. doi: 10.1016/j.corsci.2011.08.039

11. V.A. Panov, P.D. Lukovtsev and M.Z. Vainshtein, Measurement of the impedance of a copper cathode in sulfate electrolyte, Elektrokhimiya, 1971, 7, no. 7, 1053-1056 (in Russian).

12. W. Damaskin, A. Pietrij and W. Batrakow, Adsorption of organic compounds on electrodes, Plenum Press, New York, 1971, 449.

13. V.P. Batrakov, Theory of structural corrosion of metals and its application to corrosive media, Korroziya $i$ zashchita metallov, 1962, Oborongiz, Moscow, pp. 33-81 (in Russian).

14. F. Mansfeld, S.L. Jeanjaquet and M.W. Kendigan, Electrochemical impedance spectroscopy study of reactions at the metal/coating interface, Corros. Sci., 26, 1986, 735-742.

15. R.G. Buchheit, R.P. Grant, P.F. Hlava, B. Mckenzie and G.L. Zender, Local dissolution phenomena associated with $\mathrm{S}$ phase $(\mathrm{Al} 2 \mathrm{CuMg})$ particles in aluminum alloy, J. Electrochem. Soc., 1997, 2621-2628. doi: 10.1149/1.1837874

16. H.G. Bukun and A.E. Ukshe, Impedance of solid electrolyte systems (Review), Elektrokhimiya, 2009, 45, no. 1, 13-27 (in Russian).

17. Z.B. Stoinov, B.M. Grafov, B. Savova-Stoinova and V.V. Elkin, Electrochemical impedance, Nauka, 1991 (in Russian).

18. S.V. Gnedenkov and S.L. Sinebryukhov, Electrochemical impedance spectroscopy of oxide layers on titanium surface, Elektrokhimiya, 2005, 41, no. 8, 979-987 (in Russian). 
19. S. Maroie, G. Haemers and J.J. Verbist, Surface oxidation of polycrystalline [alpha] $(75 \% \mathrm{Cu} / 25 \% \mathrm{Zn})$ and [beta] $(53 \% \mathrm{Cu} / 47 \% \mathrm{Zn})$ brass as studied by XPS: influence of oxygen pressure, Appl. Surf. Sci., 1984, 17, 463-467.

20. T.L. Barr and J.J. Hackenberg, Studies of the low temperature oxidation of alloys by X-ray photoelectron spectroscopy: Cu-Zn, Appl. Surf. Sci., 1982, 10, 523-545.

21. L.P. Kazansky, Yu.E. Pronin, I.A. Arkhipushkin. XPS study of adsorption of 2mercaptobenzothiazole on a brass surface, Corros. Sci., 2014, 89, 21-29.

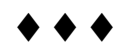

